\title{
Microevolution of bank voles (Myodes glareolus) at neutral and immune-related genes during multiannual dynamic cycles: Consequences for Puumala hantavirus epidemiology
}

\section{Dubois, Adelaide}

2017-04

Dubois , A , Galan , M , Cosson , J-F , Gauffre , B , Henttonen , H , Niemimaa , J , Razzauti , M , Voutilainen , L , Vitalis , R , Guivier , E \& Charbonnel , N 2017 , ' Microevolution of bank voles (Myodes glareolus) at neutral and immune-related genes during multiannual dynamic cycles : Consequences for Puumala hantavirus epidemiology ', Infection, genetics and evolution , vol. 49 , pp. 318-329 . https://doi.org/10.1016/j.meegid.2016.12.007

http://hdl.handle.net/10138/234004

https://doi.org/10.1016/j.meegid.2016.12.007

unspecified

publishedVersion

Downloaded from Helda, University of Helsinki institutional repository.

This is an electronic reprint of the original article.

This reprint may differ from the original in pagination and typographic detail.

Please cite the original version. 
Research paper

\title{
Microevolution of bank voles (Myodes glareolus) at neutral and immune-related genes during multiannual dynamic cycles: Consequences for Puumala hantavirus epidemiology
}

\author{
Adelaïde Dubois ${ }^{\mathrm{a}, \mathrm{b}, *}$, Maxime Galan ${ }^{\mathrm{a}}$, Jean-François $\operatorname{Cosson}^{\mathrm{a}, \mathrm{c}}$, Bertrand Gauffre ${ }^{\mathrm{d}}$, Heikki Henttonen ${ }^{\mathrm{e}}$, \\ Jukka Niemimaa ${ }^{\text {e, }}$, Maria Razzauti ${ }^{a}$, Liina Voutilainen ${ }^{\text {e,f }}$, Renaud Vitalis ${ }^{\text {a }}$, \\ Emmanuel Guivier ${ }^{\mathrm{g}}$, Nathalie Charbonnel ${ }^{\mathrm{a}}$ \\ a INRA, UMR CBGP, F-34988 Montferrier-sur-Lez, France \\ b Anses, Unité de Virologie, 31 avenue Tony Garnier, 69364 Lyon, France \\ c INRA-ANSES-ENVA, UMR 0956 BIPAR, Maisons-Alfort, France \\ d INRA, USC1339 (CEBC-CNRS), Villiers en Bois F-79360, France \\ e Natural Resources Institute Finland, FI-013012 Vantaa, Finland \\ ${ }^{\mathrm{f}}$ Department of Virology, University of Helsinki, FI-00014 Helsinki, Finland \\ g Biogeosciences, CNRS UMR 6282, Université de Bourgogne, Franche-Comté, 21000, Dijon, France
}

\section{A R T I C L E I N F O}

\section{Article history:}

Received 5 September 2016

Received in revised form 5 December 2016

Accepted 7 December 2016

Available online 9 December 2016

\section{Keywords:}

Population genetics

Immunogenetics

Host-pathogen interaction

Density fluctuations

Rodent

Adaptation

\begin{abstract}
A B S T R A C T
Understanding how host dynamics, including variations of population size and dispersal, may affect the epidemiology of infectious diseases through ecological and evolutionary processes is an active research area. Here we focus on a bank vole (Myodes glareolus) metapopulation surveyed in Finland between 2005 and 2009. Bank vole is the reservoir of Puumala hantavirus (PUUV), the agent of nephropathia epidemica (NE, a mild form of hemorrhagic fever with renal symptom) in humans. M. glareolus populations experience multiannual density fluctuations that may influence the level of genetic diversity maintained in bank voles, PUUV prevalence and NE occurrence. We examine bank vole metapopulation genetics at presumably neutral markers and immunerelated genes involved in susceptibility to PUUV (Tnf-promoter, Tlr4, Tlr7 and $M x 2$ gene) to investigate the links between population dynamics, microevolutionary processes and PUUV epidemiology. We show that genetic drift slightly and transiently affects neutral and adaptive genetic variability within the metapopulation. Gene flow seems to counterbalance its effects during the multiannual density fluctuations. The low abundance phase may therefore be too short to impact genetic variation in the host, and consequently viral genetic diversity. Environmental heterogeneity does not seem to affect vole gene flow, which might explain the absence of spatial structure previously detected in PUUV in this area. Besides, our results suggest the role of vole dispersal on PUUV circulation through sex-specific and density-dependent movements. We find little evidence of selection acting on immune-related genes within this metapopulation. Footprint of positive selection is detected at Tlr-4 gene in 2008 only. We observe marginally significant associations between $M \times 2$ genotype and PUUV genogroups. These results show that neutral processes seem to be the main factors affecting the evolution of these immune-related genes at a contemporary scale, although the relative effects of neutral and adaptive forces could vary temporally with density fluctuations. Immune related gene polymorphism may in turn partly influence PUUV epidemiology in this metapopulation.
\end{abstract}

C 2016 Published by Elsevier B.V.

\section{Introduction}

Molecular epidemiology has largely focused on the parasite side, contributing to a better understanding of the sources of infection, routes of transmission and factors influencing disease diffusion or

\footnotetext{
* Corresponding author at: INRA, UMR CBGP, F-34988 Montferrier-sur-Lez, France.

E-mail address: adelaide.dubois@supagro.inra.fr (A. Dubois).
}

pathogenesis. This approach remains less applied to hosts, although it can bring insights into factors influencing pathogen persistence, spread and evolution (Archie et al., 2009). In particular, host population genetics may enable to infer major demographic characteristics, including population size and individual movements, which play critical roles in epidemiology. Besides, many parasites lack free-living stages or have limited dispersal capacities and are therefore highly dependent of their hosts to disperse (Price, 1980). When disease transmission is 
specifically associated with a given host species, host population genetics can reveal environmental heterogeneity that may affect the spread of diseases by reducing both movements of infected hosts and contacts between infected and non-infected ones (Biek and Real, 2010). Landscape genetics studies in the host could therefore help predicting this spread of diseases and developing proactive disease management. Analysing the adaptive genetic variation that is linked to host-pathogen interactions can also improve our knowledge of disease epidemiology (see for a review Charbonnel and Cosson, 2011). Molecular epidemiology has enabled to identify host genes that are related with host susceptibility and resistance to infectious diseases. This information is essential to better assess the number of susceptible individuals within host populations. Although these genes are expected to strongly evolve under directional pathogen-driven selection, high levels of polymorphism have been observed in natural populations. This is mainly due to the interplay of neutral and selective microevolutionary forces (Charbonnel and Cosson, 2011). Because populations are usually not at equilibrium and experience demographic events such as bottlenecks, a decline in the efficiency of selection might for example be observed at these immunerelated genes (Ejsmond and Radwan, 2011; Grueber et al., 2013; Sutton et al., 2011). Besides, in particular cases including genes of the Major Histocompatibility Complex $(M h c)$, balancing selection, in addition to migration, may rapidly buffer the loss of adaptive diversity in bottlenecked populations (Oliver and Piertney, 2012; Winternitz et al., 2014).

Multiannual population density cycles are extreme cases of nonequilibrium demographic situations that could benefit from the development of host population genetics to address epidemiological questions. Such dynamics can lead to variations of effective population size (Frankham, 1995) that may significantly affect genetic diversity and population genetic structure. Drastic reductions in population size can cause a rapid decrease of allelic richness and a gradual erosion of heterozygosity, with negative consequences on adaptive potential (Bryja et al., 2007; Maruyama and Fuerst, 1985; Nei et al., 1975). However a high level of genetic diversity may sometimes persist both at neutral and immune-related genes (Berthier et al., 2006; Burton et al., 2002; Ehrich et al., 2009; Gauffre et al., 2014; Rikalainen et al., 2012; Winternitz et al., 2014). This phenomen is mainly explained by a metapopulation functioning with small demes experiencing extinctionrecolonisation during low density phase and spatial expansion with an increase of the effective migration during high abundance phase. As such, the genetic diversity is shown to remain relatively constant through time when considering all demes together (Berthier et al., 2006; Burton et al., 2002; Gauffre et al., 2014; Rikalainen et al., 2012; Winternitz et al., 2014). Density cycles can also impact dispersal rates, and consequently the distribution of genetic variability within and among populations. Several studies showed that cyclic populations of the fossorial water vole were weakly differentiated during the increasing phase of abundance but highly differentiated during the low phase of abundance, as a result of local genetic drift and low dispersal rates (Berthier et al., 2006; Berthier et al., 2005). Such cyclic dynamics could therefore have severe consequences on disease epidemiology, both ecologically and evolutionarily. Up to now, most of the studies dedicated to the genetics of these cyclic populations have been done to infer demographic characteristics and to analyze changes in immune-related genes polymorphism. The links with epidemiological risks and hostpathogen interactions still remain to be explored.

In this study, we examined this tripartite relationship between host density cycles, population genetics and epidemiology of a viral infection in the bank vole (Myodes glareolus) and Puumala hantavirus (PUUV, family of Bunyaviridae) as model species. In boreal Fennoscandia, bank vole populations undergo three to five year density cycles with high amplitude (Hanski and Henttonen, 2002; Henttonen et al., 1985). The bank vole is the reservoir of PUUV, the etiologic agent of nephropathia epidemica (NE) (Vaheri et al., 2012). Among voles, the virus is transmitted horizontally through direct contacts between individuals (i.e. bites) or indirectly via infectious aerosolized urine and feces (Bernshtein et al., 1999; Kallio et al., 2006a). The spread of PUUV is therefore closely linked to its host dispersal. PUUV infection in bank voles is chronic and mainly asymptomatic (Bernshtein et al., 1999; Meyer and Schmaljohn, 2000; Voutilainen et al., 2015a, 2015b) as maturation, winter survival and female breeding of infected individuals may be affected (Kallio et al., 2015; Kallio et al., 2007; Tersago et al., 2012). The epidemiology of PUUV in rodent populations has been well documented (Voutilainen et al., 2016). Only two studies have yet examined the connection between bank vole population and genetic microevolution of PUUV. Guivier et al. (2011) developed a landscape genetics approach in temperate zone to analyze the influence of bank vole population dynamics on PUUV spatial distribution in contrasted landscape structures. They considered genetic diversity as a proxy for estimating vole population size, isolation and migration, and found that it was highly positively correlated with PUUV prevalence and with the abundance of forest habitats at a local scale. This suggested that the persistence of PUUV was enhanced in lowly fragmented forests, where vole metapopulations are highly connected and experience low extinction rates. This result was congruent with previous correlations found between human PUUV incidence and coverage of beech tree forests (Clement et al., 2010). Besides, Weber de Melo et al. (2015) made a comparative analysis of the spatiotemporal population genetic structure of bank voles and PUUV at a smaller spatial scale. They aimed at testing the influence of vole neutral microevolutionary processes on PUUV phylodynamics. They found incongruent patterns between host and PUUV population genetic structure that were likely to arise due to the high evolutionary rate of this virus.

What is still missing to better understand the links between bank vole metapopulation dynamics and PUUV epidemiology is the characterization of the microevolutionary processes at play in the genes known to influence rodent susceptibility to hantaviruses (review in Charbonnel et al., 2014). To bridge this gap, we analyzed the genetics of bank voles at presumably neutral and PUUV associated genes (namely Tlr4, Tlr7, Tnf- $\alpha$ promoter and $M \times 2$ immune-related genes) in a metapopulation monitored during a whole demographic cycle in an highly endemic NE area of Finland. We first examined the consequences of drastic density variations on the dynamics of neutral and immunerelated genetic diversity in M. glareolus populations, both at the metapopulation scale and at the 'deme' scale. Second, we performed population genetics analyses to look for spatial barriers, like lake or rivers that could affect gene flow within the bank vole metapopulation and therefore the circulation of PUUV. We also tested whether PUUV transmission was likely to result from vole dispersal or contacts between relatives (Deter et al., 2008). Third, we investigated the possibility that selective forces may shape bank vole/PUUV interactions despite the pronounced multiannual density cycles. To this aim, we compared the genetic structure observed at immune-related genes to that measured at presumably neutral microsatellite markers, assuming that differences between the two could be the consequence of selection. We furthermore looked for associations between immune-related gene polymorphism, susceptibility to PUUV and PUUV genetic variants.

\section{Materials and methods}

\subsection{Ethic statement}

All handling procedures of wild live bank voles followed the Finnish Act on the Use of Animals for Experimental Purposes (62/2006) and took place with permission from the Finnish Animal Experiment Board (license numbers HY 45-02, HY 122-03, and HY 54-05). All efforts were made to minimize animal suffering. The species captured for this study, Myodes glareolus, neither is protected nor included in the Red List of Finnish Species. The animal trapping took place with permission from the landowners. 


\subsection{Rodent sampling and PUUV detection}

Rodents were trapped within an area of about $25 \mathrm{~km}^{2}$ of typical spruce-dominated taiga forest at Konnevesi, Central Finland $\left(62^{\circ} 34^{\prime}\right.$ $\mathrm{N}, 26^{\circ} 24^{\prime} \mathrm{E}$ ), where PUUV is highly endemic (Kallio et al., 2007; Razzauti et al., 2013; Razzauti et al., 2008; Voutilainen et al., 2015a, 2015b; Voutilainen et al., 2016). Trappings for bank vole genetic materials were carried out between 2005 and 2009 to include a whole density cycle (peak year 2005, crash year 2006, increase 2007, peak 2008, decline 2009, see (Razzauti et al., 2013; Rikalainen et al., 2012; Voutilainen et al., 2015a, 2015b), Fig. 1). Too few individuals could be sampled in crash year 2006 so that individuals sampled in 2006 were not included in the study. Trapping sessions were conducted three times per year, in the beginning and middle period of the breeding season (May, July in 2005, 2008, 2009) and in October $(2007,2009)$ to gather enough individuals when abundance levels were low. Nine sites situated at least $750 \mathrm{~m}$ apart from each other within $25 \mathrm{~km}^{2}$ were sampled (Fig. 1). Briefly, a grid of $3 \times 3$ Ugglan Special live traps (Grahnab AB, Sweden) with 15 m intervals and baited with oat seeds and potato was set in each site. Traps were checked once a day during three days, and captured bank voles were brought into the laboratory, bled through retro-orbital sinus, sacrificed, weighed, measured and sexed (for details, see Voutilainen et al. (2016)). Note that our sampling had only a negligible impact on the bank vole population dynamics and PUUV epidemiology, as deduced by comparison with results obtain from a capture-recapture study conducted within the same geographic area (Voutilainen et al., 2016). Tissue samples (toe or tip of the tail) were collected and stored in 95\% ethanol for further genetic analyses. The heart of each animal was collected, diluted into $200 \mu \mathrm{L}$ phosphatebuffered saline and frozen for latter PUUV antibody analysis. Detection of PUUV was done as described in Kallio-Kokko et al. (Kallio-Kokko et al., 2006). Serological and virological data have previously been described in Voutilainen et al. $(2016,2015)$ and Razzauti et al. (2013, 2008). Because PUUV infection in bank voles is chronic, the presence of PUUV antibodies was taken as an indicator of infection (Meyer and Schmaljohn, 2000). Yet, because juvenile voles trapped in July could be false positive because of the presence of maternal antibodies (Kallio et al., 2006b), all bank voles with low body mass ( $<17.5 \mathrm{~g}$, see Voutilainen et al., 2016) were considered juveniles carrying maternal antibodies but not PUUV infected (21 bank voles were concerned and were not considered in the analyses including seroprevalence). Sampling size and seroprevalence levels are described in details in Table S1.

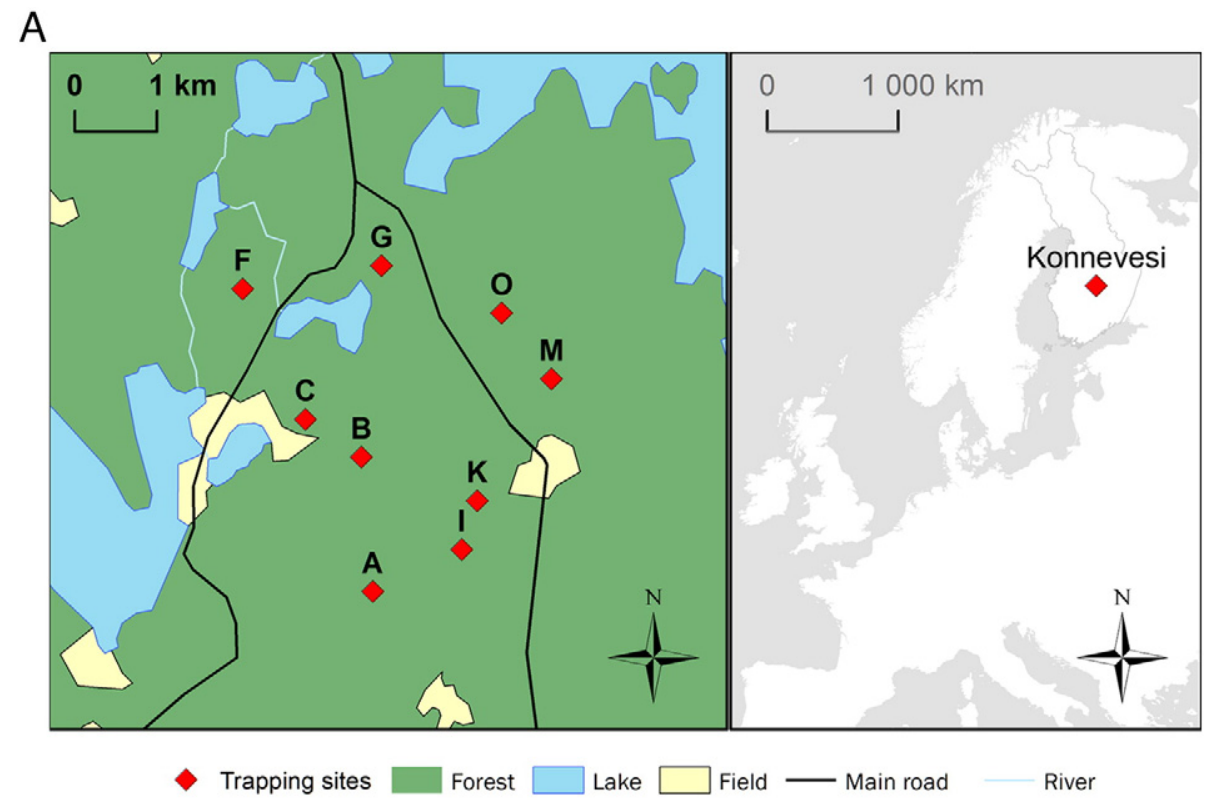

B

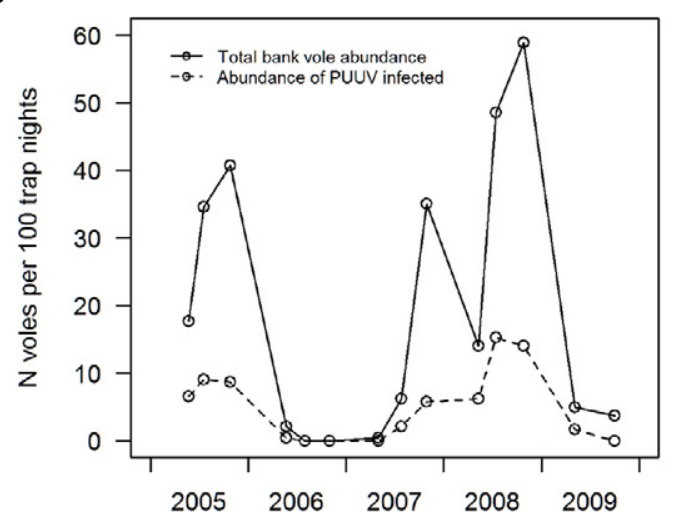

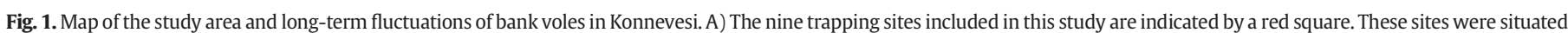

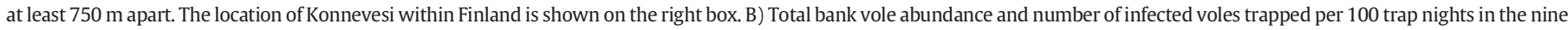

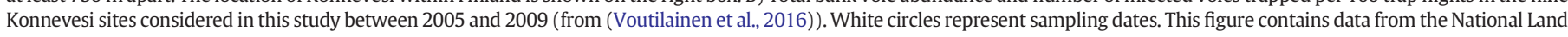
Survey of Finland Topographic Database 06/2013 (left panel) and Esri, HERE, and DeLorme (right panel). 


\subsection{DNA extraction and loci amplification}

\subsubsection{Microsatellite analyses}

Genomic DNA was extracted using the DNeasy 96 Tissue kit (Qiagen) according to manufacturer's recommendations. A final elution was done in $400 \mu \mathrm{L}$ of AE buffer (Qiagen). Samples were first genotyped at 19 unliked microsatellites loci previously published by Rikalainen et al. (Rikalainen et al., 2008) using primers and cycling conditions described in Guivier et al. (Guivier et al., 2011). Genotyping was carried out using an ABI3130 automated DNA sequencer (Applied Biosystems). Alleles were scored using GenemAPPER software (Applied Biosystems). Two loci were excluded from the genetic analyses: Cg6G11 because of the poor quality profiles obtained and $\mathrm{Cg} 5 \mathrm{~F} 11$ because it was duplicated in these populations.

\subsubsection{Candidate gene analyses}

The polymorphism of candidate genes that are relevant with regard to PUUV infections was further analyzed. These candidate genes, namely Tlr4, Tlr7, Tnf- $\alpha$ promoter and $M x 2$ were selected based on the literature of rodent or human/hantavirus interactions (Charbonnel et al., 2014; Rohfritsch et al., 2013). Tlr4 and Tlr7 genes encode for Toll-like receptors which play an important role in activating the innate immune system (Ayres and Schneider, 2012). TLR4 is a universal receptor able to detect different ligands as LPS of Gram-negative bacteria and also some viral proteins (Wlasiuk and Nachman, 2010) including hantaviral proteins (Sabeti et al., 2007). TLR7 is a receptor to virus, which is probably involved in the detection of ssRNA viruses like hantaviruses (Bowie and Haga, 2005). As both Mhc and Tlr genes encode for receptors, their polymorphism is likely to be linked to the efficiency of antigen recognition. Tnf (Tumour Necrosis Factor alpha) gene encodes for a cytokine involved in the pro-inflammatory response (Vassalli, 1992). Polymorphism within the Tnf promoter seems to be, at least partly, implicated in the regulation of $T n f$ transcription and consequently in the magnitude of the secretory response of this cytokine (Bouma et al., 1996; Wilson et al., 1997). Mx proteins are interferon-induced members of the superfamily of large GTPases. They mediate innate, antiviral resistance in rodents, as well as in other vertebrates and humans (Jin et al., 1999; Porter et al., 2006). Most Mx GTPases inhibit a wide range of RNA viruses, including members of the Bunyaviridae at an early stage in their life cycle. Thus, the efficiency of antiviral resistance seems to be mediated by $M x$ genes polymorphism.

Polymorphisms of Tnf gene promoter (Guivier et al., 2010), Tlr4 and Tlr7 gene, and $M \times 2$ exons 13 and 14, were previously investigated by the sequencing of bank voles sample from several European countries. Protocol S1 and Table S2 provide details on the list of primers and PCR conditions used to amplify the gene products. At the European scale, we identified ten single nucleotide polymorphisms (SNPs) in Tlr4 exon 3, one SNP in Tlr7 exon 3 and four SNPs in Mx2 exons 13 and 14 (Table S2, Charbonnel et al., 2014; Rohfritsch et al., 2013). Based on this previous pilot study, we selected the eight polymorphic SNPs that were not singletons (haplotype frequencies higher than 5\%, (Bollmer et al., 2011; Quéméré et al., 2015). Two of them were nonsynonymous. The software PolyPhen (Ramensky et al., 2002) was used to predict the functional impact of these non-synonymous SNPs on the translated protein, based on biochemical and physical characteristics of the amino acid replacements. The 382 individuals from Konnevesi were genotyped at these SNPs using the robust KASPar allelic-specific fluorescent genotyping system provided by KBiosciences (Hoddesdon, UK).

\subsection{Statistical analyses}

\subsubsection{Within site and within metapopulation genetic diversity}

As the number of voles trapped per site could be low, we pooled samples from May and July for each site. Moreover, because 2009 was a low-density year, we pooled all samples from all sites between May and October for this year. Further analyses were realized at two different spatial scales for each year: for each site and over the whole metapopulation. Considering microsatellites, we tested the conformity to Hardy-Weinberg equilibrium (HWE) for each locus and we analyzed linkage disequilibrium (LD) for each pair of loci using GENEPOP v4.2 (Raymond and Rousset, 1995). Corrections for multiple tests were performed using the false discovery rate (FDR) approach as described in Benjamini and Hochberg (1995). For all microsatellites and for each immune gene (Tnf, Mx2, Tlr4 and Tlr7), we estimated $N_{\mathrm{a}}$, the estimate of allelic richness corrected for minimum sample size ( 8 in our case) (El Mousadik and Petit, 1996; Goudet, 1995), the observed $\left(H_{\mathrm{o}}\right)$ and Nei's unbiased expected $\left(H_{\mathrm{e}}\right)$ heterozygosities (Nei, 1978) and Weir \& Cockerham's inbreeding coefficient $F_{\text {IS }}$ (Weir and Cockerham, 1984). Significance of $F_{\mathrm{IS}}$ (excess or deficit in heterozygotes) was assessed using 1000 permutations of alleles within each site. Similar estimates were obtained over the whole metapopulation. Calculations and tests were realized using GENETIX v4.05.2 (Belkhir et al., 1996), using FDR corrections. For these analyses, the (year $*$ site) combinations with less than eight individuals were not considered in order to avoid statistical biases.

To test whether these indices of within site and metapopulation genetic diversity varied throughout population dynamic cycles, we defined two linear mixed models, using the LME() function implemented in the NLME package for R 3.1.0 (R Core Team, 2013). Model validations were realized a posteriori by checking plots of the residuals. The first model included independently the indices of diversity $N_{\mathrm{a}}$ and $H_{\mathrm{e}}$ estimated for the sites sampled in 2005, 2007 and 2008 (2009 was not included as sample sizes per site were too low). Fixed effects included the variables year, site, type of loci (microsatellites, SNPs). We also included the pairwise interactions (year $*$ type of loci) and (year $*$ site). When the pairwise interactions were non-significant, they were removed from the model. The variable loci was included as a random effect to reflect the fact that there were initial differences in diversity between loci. The second model included the global $N_{\mathrm{a}}$ and $H_{\mathrm{e}}$ indices estimated over the whole metapopulation, for each year between 2005 and 2009 as response variables. The fixed effects year, type of loci, their pairwise interaction (year * type of loci) and the random effect loci were also added. For both models, significance of the fixed effects was assessed with analysis-of-deviance tables (function Anova). Chisquare tests with Bonferroni correction were then applied to analyze the effect of significant variables using the package phia for $\mathrm{R}$.

\subsubsection{Test for selective neutrality at microsatellite loci}

We used the software package FDIST2 (Beaumont and Nichols, 1996) to test for homogeneity in differentiation level across the final set of microsatellite loci (15 markers, see the Results section). This method is based on the principle that genetic differentiation among populations (as measured by $F_{\mathrm{ST}}$ ) is expected to be higher for loci under divergent selection, and lower for loci under balancing selection, as compared to the rest of the genome. The rationale of FDIST2 is to compute $F_{\mathrm{ST}}$ and the overall heterozygosity at each marker (computed as the average pairwise difference between all possible pairs of genes between each sample), and then to compare these values to a null distribution, generated by means of neutral coalescent simulations in a symmetrical island model at migration-drift equilibrium. Since the method was applied on microsatellite data, we used a stepwise mutation model, as implemented in FDIST2. One million simulations were performed for each analysis, assuming a 25-demes island model (and the same number of sampled demes as in the original dataset). Simulations were performed for each year independently. As in Ségurel et al. (2010), we used the averaged shifted histogram (ASH) algorithm (Scott, 2002) to characterize the probability distribution, to provide a "high probability region" that contains $90 \%, 95 \%$, or $99 \%$ of the total probability distribution, and to derive an empirical $p$-value for the joint $\left(F_{\mathrm{ST}}, H_{\mathrm{e}}\right)$ estimates at the candidate genes. 


\subsubsection{Spatial genetic structure}

We analyzed the genetic differentiation between each pair of sites using microsatellite data and Weir \& Cockerham's pairwise $F_{\mathrm{ST}}$ estimates (Weir and Cockerham, 1984). Temporal differentiation was evaluated by estimating $F_{\mathrm{ST}}$ values between sampling dates. We used exact tests implemented in GENEPOP v4.2 (Raymond and Rousset, 1995) to test for differentiation. FDR corrections were applied as described above. We next used analyses of molecular variance (AMOVA) implemented in ARLEQUIN v3.5.1.2 (Excoffier and Lischer, 2010) to quantity the proportions of genetic variation due to differences between years and between sites, using two hierarchical models (see Table 1 for details).

Spatial genetic clustering was performed using microsatellites markers in a single analysis including all years and sites to detect potential environmental factors affecting gene flow. We used the Bayesian clustering method implemented in STRUCTURE (Pritchard et al., 2000), using the admixture model with correlated allele frequencies. We performed 20 independent runs, varying the number of clusters from $K=2$ to $K=8$, using a Markov chain Monte Carlo (MCMC) made of $10^{6}$ iterations following a burn-in of 500,000 iterations. To determine the number of clusters $(K)$ best fitting our multilocus genetic data set, we used the method described in Evanno et al. (2005). We next used the FullSearch algorithm implemented in CLuMPP v1.1 (Jakobsson and Rosenberg, 2007) to assign individuals to clusters. Then, summary bar plots were built using DisTRUCT v1.1 (Rosenberg, 2004).

We finally examined the fine-scale spatial pattern of microsatellite genetic variation using inter-individual relatedness. We estimated the Li coefficient (Li et al., 1993) implemented in SpAGedi v1.4.c (Hardy and Vekemans, 2002) for each year, considering each site separately. This estimator shows a high accuracy (low bias) combined with a high precision (low variance) compared to others (Vekemans and Hardy, 2004). We performed spatial autocorrelation analyses to examine how genetic similarity between pairs of individuals changed with geographical distance. This approach was applied independently for each year, and separately for males and females to detect potential differences in dispersal behavior along cycle phases (Gauffre et al., 2014; Rikalainen et al., 2012).

\subsubsection{Links between genetic structure and PUUV epidemiology}

We first tested whether relatedness differed among seropositive and seronegative bank voles, by permuting individuals between these two classes. The seropositive juveniles presumably carrying maternal antibodies were removed from this analysis. Because pairwise data are not independent, we could not directly compare relatedness estimates between these classes of individuals using standard statistical tests (Prugnolle and Meeûs, 2002). We thus applied the procedure of Coulon et al. (2006) that consists in generating 1000 random resampling sets without replacement, such that each individual occurs only once in a given resampled set. The difference of mean relatedness $D_{i}$ between the two categories tested is then calculated for each resampling set. Under the null hypothesis, $D_{i}$ should follow a normal distribution centered on 0. Besides, on one hand, PUUV seropositive bank voles could be less related than seronegative ones if PUUV transmission mainly occurs during dispersal. On the other hand, the opposite pattern is expected if PUUV transmission occurs during winter family clustering, but up to now, this pattern has only been observed in temperate zones (see Hansson, 1986). Therefore we made no a priori assumption on the sign of the difference $D_{i}$ and thus computed two-sided tests.

Second, we evaluated the level of genetic isolation of each site relatively to the others using microsatellite markers and further analyzed the links between local genetic characteristics and PUUV seroprevalence. Site-specific $F_{\mathrm{ST}}$ values and their $95 \%$ confidence interval were estimated using the software GESTE (Foll and Gaggiotti, 2006). We then performed a logistic regression with the GLM() function implemented in R. PUUV seroprevalence was the response variable. We defined the explanatory variables as the three first principal components of a principal component analysis (PCA) of the genetic parameters $\left(H_{e}, H_{o}, F_{\mathrm{ST}}\right.$ local, $F_{I S}, N_{a}$ ) estimated for each site and each year. The variable year was not included as an explanatory variable in the logistic regression as it was highly correlated with the third axis of the PCA (Fig. 6).

\subsection{5. $F_{S T}$ outlier test to detect signatures of selection in candidate genes}

We evaluated whether the genetic differentiation at immunerelated genes departed from the null distribution expected at neutrality. The rationale was to compute $F_{\mathrm{ST}}$ and the overall heterozygosity at each immune-related gene, and then to compare these values to a null distribution, obtained by means of neutral coalescent simulations in a symmetrical island model at migration-drift equilibrium. These simulations were generated conditionally on the overall $F_{\mathrm{ST}}$ estimate calculated from the microsatellite markers only $\left(F_{\mathrm{ST}}=0.0209\right.$ in 2005; $F_{\mathrm{ST}}=0.0182$ in 2007 and $F_{\mathrm{ST}}=0.0252$ in 2008). Therefore, the null distribution is independent from the level of differentiation observed at the candidate genes using an infinite allele model. For the analysis of the SNP data, we used a version of the software package DFDIST, which we modified to generate bi-allelic co-dominant data (Ségurel et al., 2010). An infinite allele model of mutation was considered, with $\theta=2 n N \mu=0.1$ (where $n=25$ is the number of demes of size $N$, and $\mu$ is the mutation rate) and only the simulations resulting in bi-allelic data were retained. One million simulations were performed for each analysis, assuming a 25-demes island model (and the same number of sampled demes as in the original dataset). For all simulations, the maximum frequency of the most common allele allowed was set to 0.99 . These analyses were realized for each year independently. We characterized the "high probability regions" (based on the level of differentiation at neutral markers) and the empirical $p$-values at the candidate genes using the averaged shifted histogram (ASH) algorithm (Scott, 2002), as in Ségurel et al. (2010). Because the true demographic history of M. glareolus populations is likely to depart from the underlying assumptions of FDIST2 and the modified DFDIST, especially with

Table 1

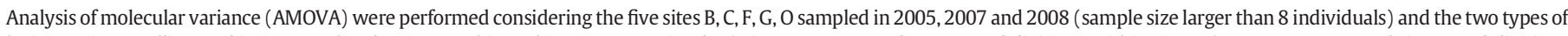

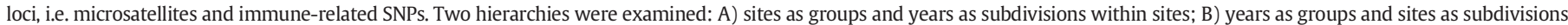
within years.

\begin{tabular}{|c|c|c|c|c|c|c|c|c|}
\hline \multirow{2}{*}{$\begin{array}{l}\text { A) } \\
\text { Source of variation }\end{array}$} & \multicolumn{4}{|c|}{ Microsatellites } & \multicolumn{4}{|l|}{ SNPs } \\
\hline & DF & Variance components & Percentage of variation & $p$ & $\mathrm{DF}$ & Variance components & Percentage of variation & $p$ \\
\hline Among sites & 4 & 0.042 & 0.65 & 0.0006 & 4 & -0.003 & -0.553 & 0.677 \\
\hline Among years within sites & 10 & 0.128 & 1.98 & $<10^{-5}$ & 10 & 0.009 & 1.914 & 0.064 \\
\hline Among individuals within year & 449 & 6.292 & 97.37 & $<10^{-5}$ & 443 & 0.482 & 98.64 & 0.066 \\
\hline B) & \multicolumn{4}{|c|}{ Microsatellites } & \multicolumn{4}{|c|}{ SNPs } \\
\hline Source of variation & $D F$ & Variance components & Percentage of variation & $p$ & $D F$ & Variance components & Percentage of variation & $p$ \\
\hline Among years & 2 & -0.003 & -0.04 & 0.731 & 2 & -0.004 & -0.743 & 0.865 \\
\hline Among sites within years & 12 & 0.166 & 2.570 & $<10^{-5}$ & 12 & 0.009 & 1.966 & 0.036 \\
\hline Among individuals within sites & 449 & 6.292 & 97.47 & $<10^{-5}$ & 443 & 0.482 & 98.78 & 0.064 \\
\hline
\end{tabular}


respect to the hypothesis of stable demography, we investigated to what extent the approach to detect signatures of selection was robust to temporal variations in population size (see Supplementary Appendix S1).

\subsubsection{Association between genotypes at immune-related genes and PUUV serology}

Because candidate gene polymorphism was expected to be related to bank vole susceptibility to PUUV, we searched for associations between immune variations and PUUV serology which was used as a proxy of PUUV infection status (Guivier et al., 2010). The relative risk (RR) associated with each allele of interest was estimated following (Haldane, 1956). The significance of the association between these alleles and vole serological status were analyzed using Fisher exact tests and Bonferroni sequential corrections. Similar analyses were performed for seropositive bank voles $(N=46)$ to look for potential associations between PUUV diversity (PUUV genogroups, see Razzauti et al., 2013, Razzauti et al., 2008) and bank vole immune-related gene polymorphism.

\section{Results}

3.1. Validation of microsatellite marker and candidate immune-related gene polymorphism

Two microsatellite loci, Cg2F2 and Cg13F9, showed important deviations from HWE suggesting the presence of null alleles. They were removed from the analyses. The analyses performed using FDIST2 revealed that none of these microsatellites departed from neutral expectation (Supplementary Material Fig. S1). Thus, our final dataset included 382 bank voles genotyped at 15 microsatellites loci.

Eight SNPs were genotyped over all other candidate genes: four SNPs appeared to be monomorphic out of the five SNPs analyzed within Tlr4 and were excluded from the data. No polymorphism was found within Tlr7. Finally, polymorphism of a single SNP was analyzed for each of the following immune-related genes: $M x 2$, $T n f$ promoter and Tlr4.

\subsection{Genetic diversity at local and global scales}

A total of 43 pairs of microsatellites exhibited significant LD over the 684 tested (6\%) after FDR correction. The loci involved differed across years and sites. One out of 60 tests for deviation from HWE was significant, and concerned the locus $\mathrm{Cg} 16 \mathrm{H} 5$. A deficit in heterozygotes was observed for Cg16H5 in 2007, at the metapopulation scale. We used MiCROCHECKER software to analyze the hypothesis that null alleles could drive this deficit in heterozygotes. It indicated the possibility of null alleles with estimated frequencies of 0.111 , having therefore little chance to bias further genetic parameter estimates (Chapuis and Estoup, 2007).

Supplementary Table S1 gives the range of diversity estimates, across years and sites, and at the whole metapopulation scale, for microsatellites markers and immune-related genes. Detailed results of the GLMs used to test the effects of bank vole population cycles on genetic diversity indices are presented in Supplementary Table S4. $\mathrm{H}_{\mathrm{e}}$ and $N_{\mathrm{a}}$ estimates were higher at microsatellite loci than at immunerelated genes at the local (within site $-H_{e}: X^{2}{ }_{1}=160.3, p<10^{-4} ; N_{\mathrm{a}}$ : $X^{2}{ }_{1}=45.62, p<10^{-4}$ ) and global scales (within metapopulation $-H_{e}$ : $X^{2}{ }_{1}=159.3, p<10^{-4} ; N_{\mathrm{a}}: X^{2}{ }_{2}=19.48, p=10^{-4}$, Fig. 2$)$. At the local scale, $H_{\mathrm{e}}$ estimates also varied among years $\left(X^{2}{ }_{2}=6.789, p=0.034\right)$, with lower estimates observed in 2008 than in $2007\left(X^{2}{ }_{1}=6.939\right.$, $p=0.025)$. At a global scale, $N_{\mathrm{a}}$ estimates varied among years $\left(X^{2}{ }_{3}=\right.$ $8.492, p=0.037)$, with lower estimates observed in 2009 compared to $2005\left(X^{2}{ }_{1}=8.286, p=0.024\right)$. Immune-related SNPs exhibited strong temporal changes of diversity at the global scale compared to other loci $\left(H_{\mathrm{e}}\right.$; interaction year $*$ type of loci: $\left.X^{2}{ }_{3}=32.84, p<10^{-4}\right)$. In particular, Mx2_162 and Tlr4_1662 exhibited lower $H_{\mathrm{e}}$ levels in 2005 compared to 2009 (from 0.25 to 0.35 and 0.21 to 0.34 respectively), mainly as a result of an increase in frequency of the less common variant between these two years.
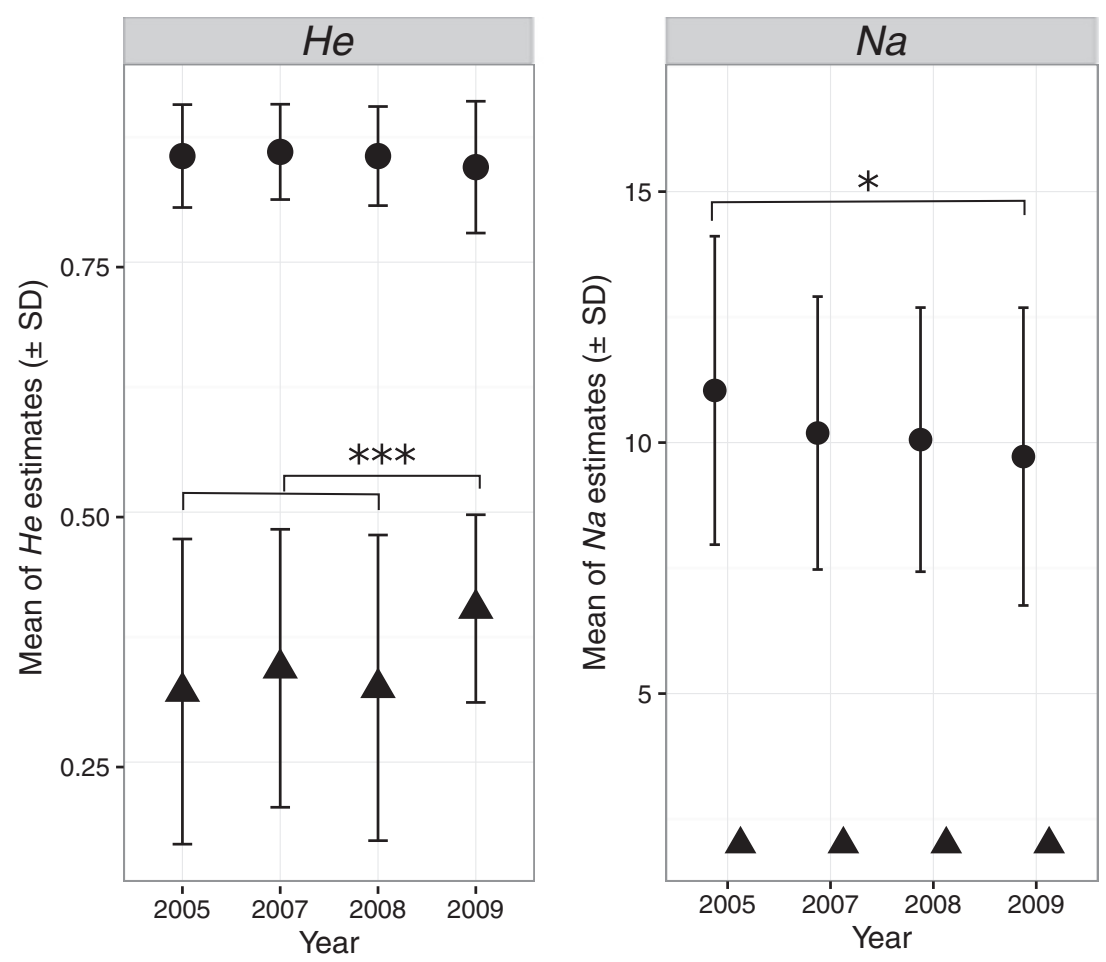

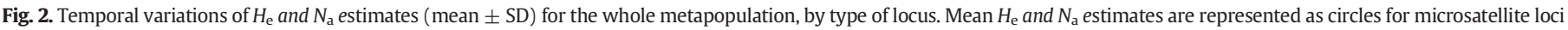

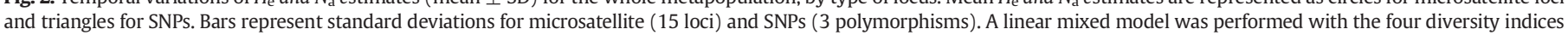
estimated over the whole metapopulation sampled in 2005, 2007, 2008 and 2009. Significant differences between years are indicated by asterisks $\left({ }^{*} p<0.05\right.$; $\left.{ }^{* * *} p<0.001\right)$. 


\subsection{Spatial genetic structure}

Spatial pairwise $F_{\mathrm{ST}}$ estimates ranged between 0.003 and 0.056 for microsatellites, and -0.077 and 0.270 for SNPs (Table S5). At the scale of the metapopulation, temporal pairwise $F_{\mathrm{ST}}$ ranged between 0.003 and 0.017 at microsatellites, with high estimates corresponding to pairs of sampling date including the crash year 2009. None of these estimates were significant for immune-related genes (Table S6).

AMOVA analyses revealed significant spatial genetic structure at microsatellites only, and significant variation among sites within years for all loci (Table $1 \mathrm{~A})$.

AMOVA analyses also revealed an absence of temporal genetic differentiation over the whole metapopulation whatever the loci considered, and significant variation among years within sites for microsatellites. No such local temporal genetic changes were detected at immune-related SNPs (Table 1B).

Clustering analyses based on microsatellites performed over the whole dataset revealed three clusters that did not discriminate either years or sites. All voles were assigned to these three genotypic groups (Fig. 3A, B). It is therefore likely that a complete absence of spatiotemporal structure $(K=1)$ is the best hypothesis to explain this result.

Spatial autocorrelograms revealed a strong decrease of relatedness between individuals with geographic distance, whatever the sex and year considered (Fig. 4). Nevertheless, mean relatedness of females was slightly higher at very small spatial scale (within sampling site or in the first surrounding sites distant from $<1 \mathrm{~km}$ ) during peak years (respectively 0.04 and 0.05 in 2005 and 2008) than during the increase phase (0.03 in 2007). Contrastingly, relatedness between males was higher within sites during the increase phase (0.03) than during peak years (respectively 0.01 and 0.02 in 2005 and 2008).

\subsection{Links between genetic structure and PUUV epidemiology}

For each year, the estimates of mean relatedness among seropositive and seronegative voles in the metapopulation showed very low and similar values, respectively $r=-0.006$ and $r=6.10^{-4}$ in $2005(p=$ 0.344), $r=-0.014$ and $r=-0.006$ in 2007 ( $p=0.857)$, $r=-0.009$ and $r=0.005$ in $2008(p=0.333)$ and $r=-0.050$ and $r=0.030$ in 2009 ( $p=0.399)$.

Site-specific $F_{\mathrm{ST}}$ estimates at microsatellite markers (computed using the GESTE software) ranged between 0.009 and 0.063 , showing various levels of genetic isolation of sites within the bank vole metapopulation (Table S1). The first axis of the PCA based on microsatellite genetic parameters (PC1) explained $57.4 \%$ of the variability and revealed a strong opposition between these local $F_{\mathrm{ST}}$ estimates and the other genetic features describing genetic diversity, especially $H_{\mathrm{e}}$ and $N_{\mathrm{a}}$ (Fig. 5A). This axis therefore illustrated the opposing impacts of genetic drift and migration on local genetic diversity. The second axis of the PCA (PC2) accounted for $36.5 \%$ of the total variability, and opposed microsatellite genetic parameters reflecting the deviation from Hardy-Weinberg equilibrium within site $\left(H_{o}\right.$ and $\left.F_{i s}\right)$. The third PCA axis (PC3) explained 5.1\% of the variability and contrasted the diversity indices $N_{a}$ and $H_{e}$ (Fig. 5B). The best and the most parsimonious model explaining PUUV seroprevalence using site coordinates on these three axes included PC3 only $(z$ value $=2.119, p=0.034)$. PUUV prevalence therefore seemed mostly related to local changes in microsatellite allelic richness associated with the population cycle, PUUV seroprevalence reaching higher levels during the increase year (2007).

\subsection{Detection of signatures of selection}

The patterns of differentiation conditional on heterozygosity differed between genes and years (Fig. 6). Departure from neutral expectation was observed at the Tlr4-1662 SNP in 2008 only. $F_{\mathrm{ST}}$ estimate lay outside the $95 \%$ confidence region of the null distribution, showing that the Tlr4-1662 SNP was more differentiated $\left(F_{\mathrm{ST}}=0.076\right)$ than expected under neutrality (Fig. 6C), showing a significant signature of positive selection $(p=0.037)$. Mx2-162 SNP exhibited low $F_{\mathrm{ST}}$ estimates $\left(F_{\mathrm{ST}}=-0.030\right.$ in $2007 ; F_{\mathrm{ST}}=-0.013$ in 2008), suggesting potential signature of balancing selection $(p=0.090)$. No significant departure

A

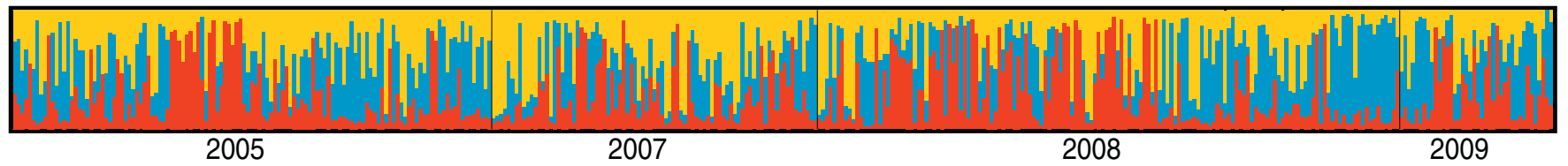

B

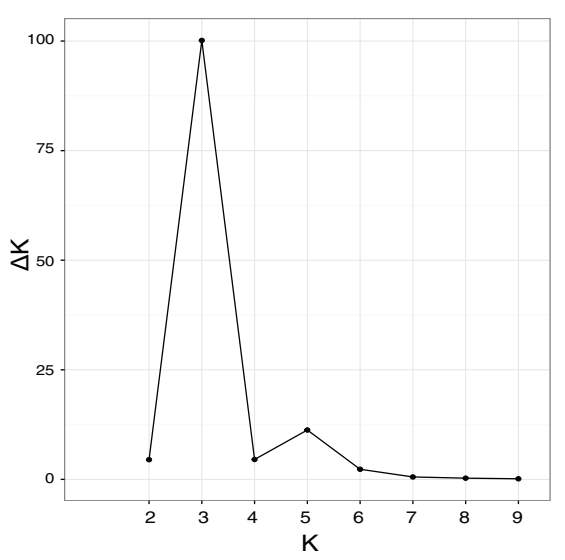

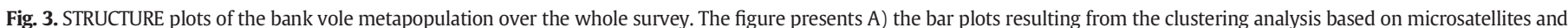

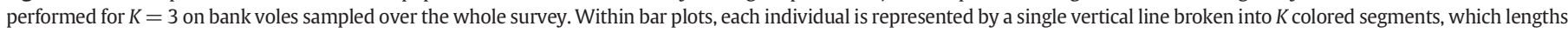

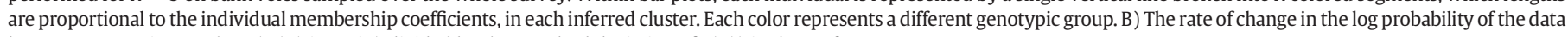
between successive $K$ values $\left(\Delta(K)\right.$ i.e. $\mathrm{L}^{\prime \prime}(K)$ divided by the standard deviation of $\left.\mathrm{L}(K)\right)$ is shown for $K=2$ to $K=9$. 


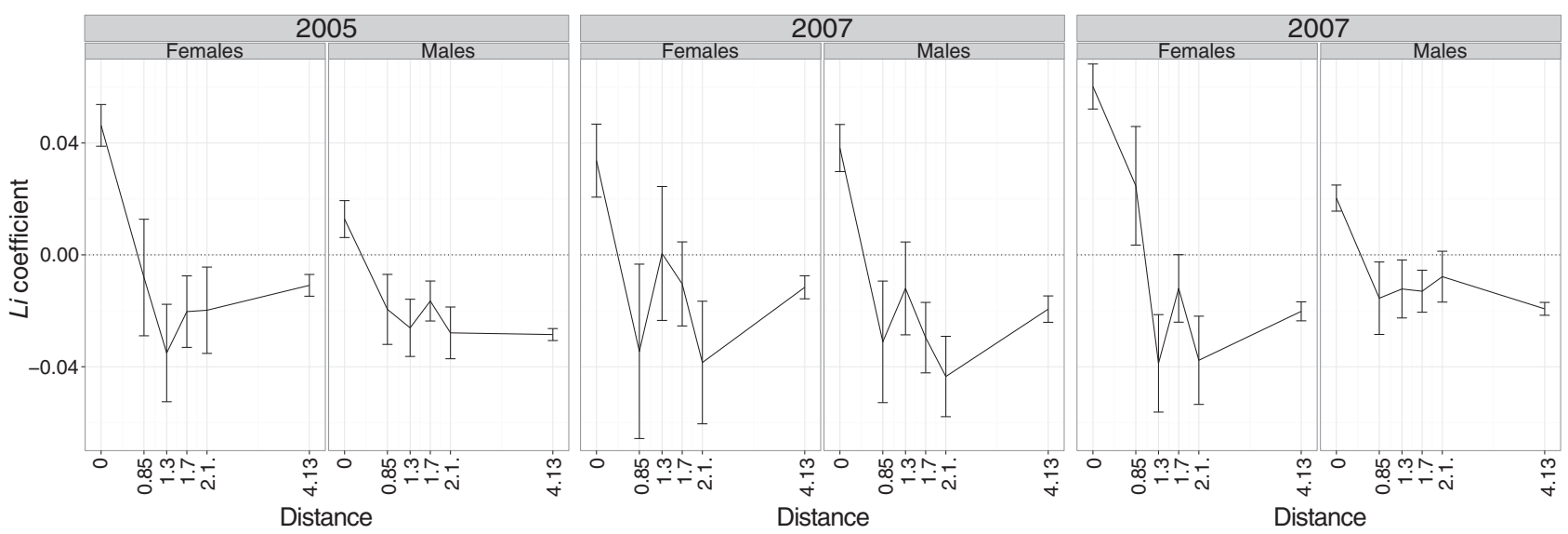

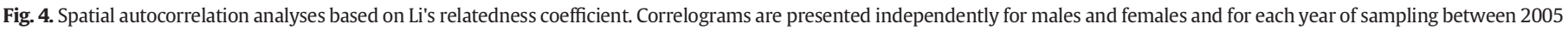
and 2008. Geographic distances classes are indicated in km. The mean and standard error of Li's relatedness coefficient (Li et al., 1993) are indicated for each class.

from neutral expectations was found for Tnf. Investigating to what extent the approach to detect signatures of selection was robust to temporal variations in population size, we found virtually no difference between the distributions of $F_{\mathrm{ST}}$ conditional on heterozygosity across different scenarios of population size changes (see Supplementary Material Fig. S2), which justifies a posteriori the use of our approach to detect signatures of selection on cyclic populations.

\subsection{Associations between immune-related genotypes and PUUV}

We found a marginally significant association between bank vole polymorphism at Mx2-162 SNP (presence/absence of G) and PUUV genogroup. Individuals carrying the $\mathrm{G}$ nucleotide at Mx2-162 SNP were at higher risk of being infected with PUUV reassortants ( $\mathrm{S}$ segment, genogroup A \& M segment genogroup B or S segment, genogroup B \& M segment genogroup $A ; R R=7.500, p=0.052$ ) than those carrying the $\mathrm{C}$ base only.

\section{Discussion}

In this study, we analyzed the genetic variation of a bank vole metapopulation, experiencing three-year population density cycles, at microsatellite loci and immune-related genes to examine the potential interactions between microevolutionary processes and PUUV epidemiology. Overall, we showed that neutral and adaptive genetic variability was maintained through years despite repeated demographic bottlenecks. Rapid increase in vole density, the absence of landscape barriers and high gene flow seemed to counterbalance the effects of genetic drift, which may explain the absence of founder effects observed in PUUV population throughout vole population cycles (Razzauti et al., 2013). In addition, our results suggest that PUUV circulation results from vole dispersal through sex-specific and density-dependent movements, but not from contacts between relatives. Finally, we found little evidence of selection acting on immune-related genes within this metapopulation. We characterized departure from neutral expectations at Tlr4 gene in 2008 only, and marginal associations between PUUV genetic variants and bank vole alleles at $M x 2$.

Neutral evolutionary processes therefore seemed to be the main drivers affecting the evolution of these immune-related genes. This genes polymorphism might in turn partly influence PUUV epidemiology in this metapopulation.

\subsection{Genetic drift, bank vole dispersal and PUUV epidemiology}

In boreal Fennoscandia, bank vole populations experience strong multiannual fluctuations in abundance, with peaks occurring every
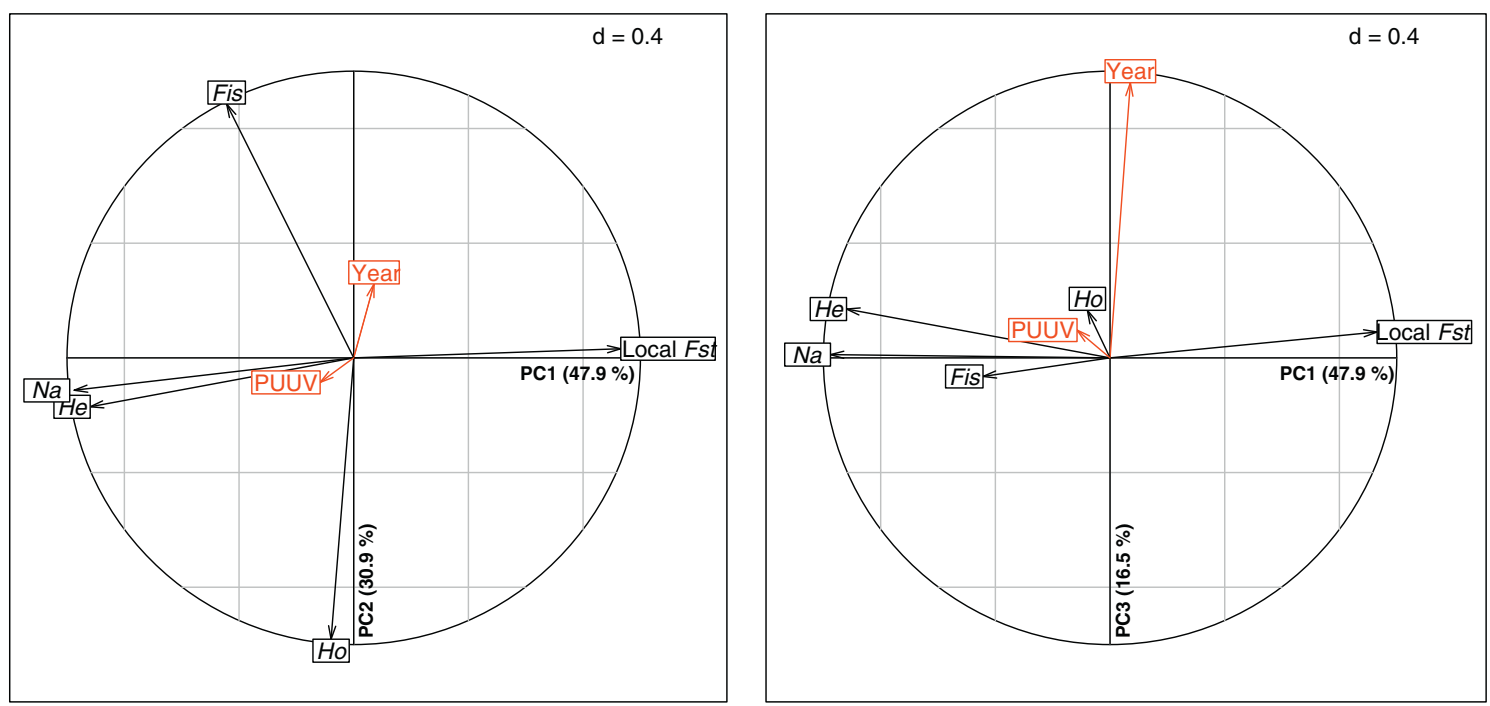

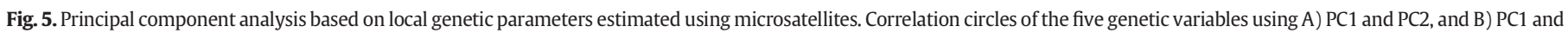
PC3. Puumala seroprevalence and year were included as supplementary variables. 


\section{5}

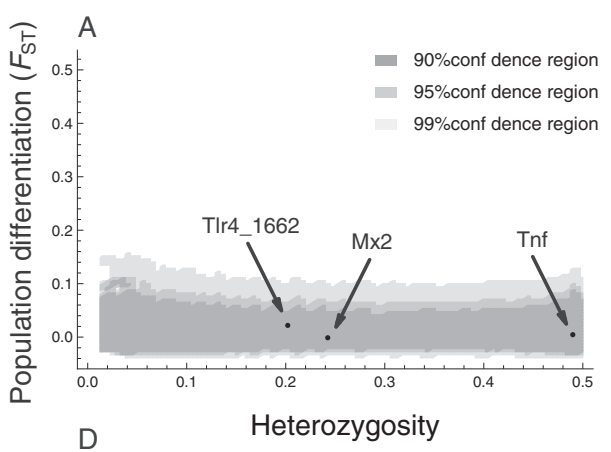

2007

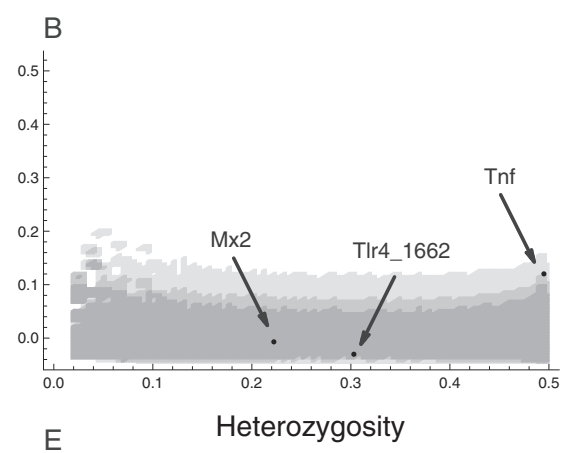

2008

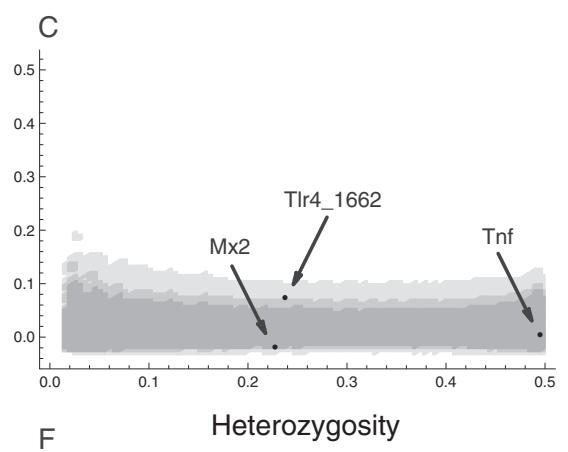

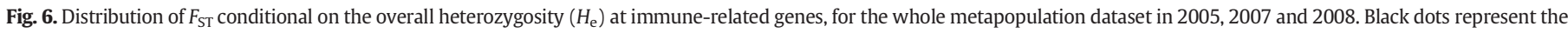

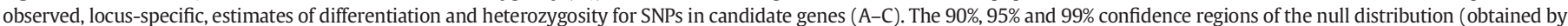

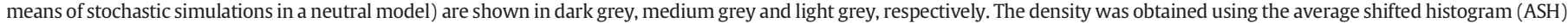
algorithm (Scott, 2002) with smoothing parameter $m=2$.

three to five years and abundance varying by a factor 500 between low and peak phases (Hansson and Henttonen, 1988). Such regular and severe declines in population size are expected to affect neutral genetic variation through genetic drift. However, several studies have shown that cyclic rodent populations maintained high levels of genetic diversity, at least at a metapopulation scale (Berthier et al., 2005; Ehrich et al., 2009; Ehrich et al., 2001; García-Navas et al., 2015; Gauffre et al., 2014; Winternitz et al., 2014). Marginal and temporal decreases in allelic richness were previously observed by Rikalainen et al. (2012), who studied Finnish bank vole populations at a larger scale $\left(100 \mathrm{~km}^{2}\right)$ around Konnevesi. Our results provided similar patterns, with high levels of heterozygosity and allelic richness being observed whatever the cycle phase considered. We detected a decrease in allelic richness in the crash phase of 2009 at the scale of the metapopulation. This loss of diversity might be only transient as no decrease could be observed after the 2006 crash year. Therefore, fluctuations in population size did not lead to strong signature of bottleneck in the genetic data, whatever the spatial scale considered. Similarly, Razzauti et al. (2013) did not find any evidence of founder effects affecting PUUV diversity in the area including this vole metapopulation. Significant loss of PUUV variants were detected in 2009 only, with the complete absence of variants from one of the two PUUV genogroups otherwise detected since 2005. These patterns could be explained by the low sampling size in 2009. But it is likely that the low phase is usually too short to impact host genetic diversity, and/or that strong bank vole gene flow might compensate for genetic drift (Ehrich et al., 2009). Genetic patterns of temporal and spatial differentiation supported the hypothesis that dispersal among sites may rapidly counterbalance the potential loss of genetic diversity experienced by vole and PUUV populations. Although significant temporal genetic differentiation was locally detected between years, low estimates of temporal genetic differentiation were detected at the scale of the metapopulation. These estimates were slightly higher when comparing pairs of sampling dates before and after decline (especially in 2009). This result corroborated the transient impact of genetic drift on the distribution of genetic variability, and the importance of gene flow occurring after population crash, once vole population size increased again. The relative temporal genetic stability of this metapopulation was also supported by the clustering analysis performed over the whole survey, as it did not reveal any consistent spatial structuring. Altogether, these results emphasized the absence of environmental heterogeneity within the studied area, a typical boreal forest, that could disrupt bank vole gene flow and in turn, PUUV dispersal among sites. The possibility for voles to move all around this area provides an explanation for the absence of spatial structure detected in PUUV population across this area (Razzauti et al., 2013).
Spatial autocorrelation analyses highlighted changes in the bank vole spatial genetic structure from year to year, that probably resulted from density fluctuations favouring dispersal and population turnover (e.g. Ehrich et al., 2009; Rikalainen et al., 2012)). This raised the question of density-dependent dispersal, that is, whether dispersal rate increased during low phase or with increasing population size (see Pilot et al. (2010) for references and predictions). As evidenced by Rikalainen et al. (2012) and Gauffre et al. (2014), our study suggested patterns of sex-specific and density-dependence dispersal. Negative density dependent migration of females could underlie the local changes in relatedness observed between low density and peak years. The slightly lower relatedness observed during the increase phase could hence be explained by the colonization of new empty sites by females. The high levels of relatedness observed during 2005 and 2008 could reflect female phylopatry and low migration (see Le Galliard et al., 2012) once population size has reached high abundance. On the other hand, the lower levels of relatedness observed in peak years compared to the increase phase when focusing on males could result from their high dispersal rate and high gene flow once density reached high levels. The social behavior in M. glareolus is likely to underlie these variations of dispersal through time. Dispersal is strongly connected with maturation, which is season and density-dependent. Maturation phases and connected dispersal of young maturing voles are shorter in the peak than in the increase summer, as they only concern the first litter produced in spring. This sex-biased density dependent migration could be of main importance in shaping PUUV epidemiology. Indeed, a male bias in PUUV infection was detected in Konnevesi in overwintered, breeding bank voles, whereas a female bias was seen in summer-born breeding animals probably as a result of more frequent contact with old (infected) males or aggressive encounters with other breeding females during the territory establishment (Voutilainen et al., 2016). In addition, PUUV seropositive voles were found to be more abundant during the highdensity years of the dynamic cycle (increase and peak autumn-winters), as confirmed by the strong correlation observed in this study between PUUV seroprevalence and two indices of genetic diversity differentiating peak versus low-density years. We could therefore suggest that during low-density phase, female voles could play a role in the colonization of empty sites and consequently in the transmission of PUUV. During peak years, males would be responsible for repeated dispersal events and gene flow, therefore contributing to PUUV transmission.

\subsection{Impact of metapopulation dynamics on immune-related gene polymorphism}

Whether migration and natural selection can counterbalance the effect of drift on immune gene polymorphism in populations 
experiencing drastic fluctuations remains an open research topic, as empirical data have revealed contrasted patterns. From an ecoevolutionary perspective, this question is of uttermost importance as a loss of genetic variation could result in dampened adaptive capability, which is especially problematic when faced with rapidly evolving pathogens. A recent meta-analysis showed that a greater loss of genetic diversity was generally seen at Mhc genes rather than at neutral loci, potentially because of the uneven distribution of haplotypes before the bottleneck (Sutton et al., 2011). Here, we studied four genes contributing to immunity, with polymorphism analyzed within protein coding regions ( $T l r s, M x 2$ ) or in the promoter ( $T n f$ ). Variation at these immunerelated genes has previously been shown to be associated with rodent responses to PUUV infections (Charbonnel et al., 2014).

Our study first enabled to investigate the relative role of neutral processes and selection in shaping the geographic variation of immune gene diversity in this cyclic bank vole metapopulation. As predicted under genetic drift only, reduction of immune-related gene variability was observed at SNPs, with different patterns detected according to the immune-related gene considered. Loss of less frequent variants was for example locally observed after the 2006 crash at Mx2_162 SNP only. However, this impact of genetic drift on immune-related genes seemed minor and very transient, as there were no such significant temporal changes in allelic frequencies at other SNPs.

Dispersal can be invoked to explain that allelic diversity was recovered once vole abundance increased, as previously seen in Winternitz et al. (2014).

\subsection{Little evidence of selection acting on immune-related gene polymorphism}

Model-based simulations revealed little evidence of departures from neutrality for immune-related gene polymorphisms. The Tlr4-1662 SNP showed signature of positive selection, in 2008 only. Tlr4 is part of Tlrs gene family and is involved in coevolutionary processes with a wide variety of pathogens (Akira et al., 2006; Hughes and Piontkivska, 2008). Several studies recently emphasized the impact of historical and contemporary positive selection on Tlr4 gene polymorphism in rodents (Fornůsková et al., 2014; Fornůsková et al., 2013; Turner et al., 2012), and it is likely that pathogens might mediate this selection. The signature of positive selection observed in this study might reflect spatial heterogeneity in the whole pathogen community or in one/few pathogens recognized by TLR4. Temporal variations of selection patterns at immune-related genes have previously been described in arvicoline rodents experiencing population cycles. Bryja et al. (2007) found densitydependent changes in selection pressure throughout a complete density cycle of the montane water vole (Arvicola scherman), and these changes were detected at only one Mhc class II gene over the two examined. In cyclic populations of field vole (Microtus agrestis), Turner et al. (2012) detected signature of selection acting on only two genes encoding cytokines over the twelve immune-related genes examined. Such results could be mediated by temporal heterogeneity in pathogen pressure (e.g. Fraser et al., 2010) that may have a strong selective effect even in a few generations (e.g. Oliver and Piertney, 2012). Because positive selection was observed in the peak year, when gene flow is important once voles get mature in spring and should homogenize directly transmitted pathogens, potentially other candidates than PUUV should preferentially be searched among vector-borne agents (e.g. bacteria like Bartonella sp., Borrelia sp.) or pathogens able to survive outside their hosts (e.g. ectoparasites).

A marginally significant pattern of balancing selection was observed at $M \times 2$ gene in 2008 and we found a tendency for PUUV reassortants to be associated with a particular $M \times 2$ genotype. $M x 2$ gene encodes for proteins that provide immunity against viruses replicating in the cytoplasm, including hantaviruses (Jin et al., 2001; Lee and Vidal, 2002). The SNP detected under selection and associated with PUUV variants was located within the leucine zipper motif of the C-terminal GTP effector domain, where mutations can affect the antiviral efficacy of Mx proteins (Janzen et al., 2000; Kochs and Haller, 1999; Zürcher et al., 1992). Balancing selection could be mediated by spatiotemporal heterogeneity in candidate viruses including PUUV (Guivier et al., 2013; Razzauti et al., 2013; Razzauti et al., 2008), and it would be stronger during peak year when dispersal may homogenize their distribution within the area.

Finally, we did not confirm the signatures of positive selection that were previously detected at the -296 SNP of Tnf- $\alpha$ promoter between $\mathrm{NE}$ endemic and non-endemic areas, at regional and European geographical scales (Guivier et al., 2013; Guivier et al., 2010). Several explanations can be evoked to explain the absence of footprint of selection observed in this study. In particular, the statistical methods and the sampling design used in this study might prevent from detecting local adaptation mediated by pathogens (Lotterhos and Whitlock, 2014). First, some of the underlying assumptions of our tests to detect departures from neutral expectation are likely to be violated in this study. In particular, FDIST2 and the modified DFDIST are based on an island model at migration-drift equilibrium, while the true demographic history of M. glareolus is characterized by non-equilibrium population dynamics. However, we have shown by means of simulations (see Supplementary Appendix S1 and Supplementary Fig. S2) that the approach was robust to temporal variations in population size, at least in the range of differentiation level observed in our data, which is consistent with the idea that the distribution of $F_{\mathrm{ST}}$ estimates should be robust to the vagaries of demographic history (Beaumont, 2005). Second, $F_{\mathrm{ST}}$ outlier tests have low statistical power to detect balancing selection (Beaumont and Balding, 2004) and weak divergent selection (e.g. (Wachowiak et al., 2009). The spatial scale examined in this study might be too small to cover different selective environments mediated by pathogens and to lead to strong effective selection. It would therefore be interesting to perform similar analyses at a larger scale (about $100 \mathrm{~km}^{2}$ ) to cover contrasted 'pathogenic landscapes' but still limiting the potential confounding effects due to neutral population structure. Finally, we cannot discard the possibility that we may have missed important immune related genes evolving under strong effective selection in this metapopulation.

In conclusion, this study provided evidence for the role of vole dispersal on PUUV circulation through sex-specific and densitydependent movements. We also revealed that multiannual dynamic cycles were likely to affect the diversity of immune-related genes involved in susceptibility to PUUV, mainly through neutral microevolutionary processes. In the future, we recommend both the development of population genome-wide scan approaches that require no a priori on immune-related candidate genes and the analysis of metapopulations covering heterogeneous landscapes with regard to pathogens, to better assess the influence of selection on rodent/hantavirus interactions. Preliminary high-throughput characterization of rodent microbial communities (e.g. Galan et al., 2016) should enable to define the optimal geographical scale to consider for such studies, i.e. large enough to encompass contrasted environments with regard to pathogen community diversity and structure, but still limited to remain close from an island model of demographic history.

Supplementary data to this article can be found online at http://dx. doi.org/10.1016/j.meegid.2016.12.007.

\section{Fundings}

This research has been partially funded by EU grants GOCE-CT-2003010284 EDEN and FP7-261504 EDENext, and the paper is catalogued by the EDENext Steering Committee as EDENext 405 (http://www. edenext.eu). AD is currently funded by an INRA-EFPA/ANSES fellowship.

\section{Acknowledgments}

Microsatellite data used in this work were produced through the technical facilities of the Centre Méditerranéen Environnement 
Biodiversité (CeMEB). We are grateful to Audrey Rohfritsch and Viola Walther for the identification of SNPs at immune gene during the pilot study. We are grateful to Jeremy Gaudin for technical assistance and preliminary analyses.

\section{References}

Akira, S., Uematsu, S., Takeuchi, O., 2006. Pathogen recognition and innate immunity. Cell $124,783-801$

Archie, E.A., Luikart, G., Ezenwa, V.O., 2009. Infecting epidemiology with genetics: a new frontier in disease ecology. Trends Ecol. Evol. 24, 21-30.

Ayres, J.S., Schneider, D.S., 2012. Tolerance of infections. Annu. Rev. Immunol. 30, 271-294.

Beaumont, M.A., 2005. Adaptation and speciation: what can Fst tell us? Trends Ecol. Evol. $20,435-440$

Beaumont, M.A., Balding, D.J., 2004. Identifying adaptive genetic divergence among populations from genome scans. Mol. Ecol. 13, 969-980.

Beaumont, M.A., Nichols, R.A., 1996. Evaluating loci for use in the genetic analysis of population structure. Proc. R. Soc. B Biol. Sci. 263, 1619-1626.

Belkhir, K., Borsa, P., Chikhi, L., Raufaste, N., Bonhomme, F., 1996. GENETIX 4.05, Logiciel Sous Windows TM Pour la Génétique des Populations.

Benjamini, Y., Hochberg, Y., 1995. Controlling the false discovery rate: a practical and powerful approach to multiple testing. J. R. Stat. Soc. 57, 289-300.

Bernshtein, A.D., Apekina, N.S., Mikhailova, T.V., Myasnikov, Y.A., Khlyap, L.A., Korotkov, Y.S., Gavrilovskaya, I.N., 1999. Dynamics of Puumala hantavirus infection in naturally infected bank voles (Clethrinomys glareolus). Arch. Virol. 144, 2415-2428.

Berthier, K., Galan, M., Foltête, J.C., Charbonnel, N., Cosson, J.F., 2005. Genetic structure of the cyclic fossorial water vole (Arvicola terrestris): landscape and demographic influences. Mol. Ecol. 14, 2861-2871.

Berthier, K., Charbonnel, N., Galan, M., Chaval, Y., Cosson, J.-F., 2006. Migration and recovery of the genetic diversity during the increasing density phase in cyclic vole populations. Mol. Ecol. 15, 2665-2676.

Biek, R., Real, L., 2010. The landscape genetics of infectious disease emergence and spread. Mol. Ecol. 19, 3515-3531.

Bollmer, J.L., Ruder, E.A., Johnson, J.A., Eimes, J.A., Dunn, P.O., 2011. Drift and selection influence geographic variation at immune loci of prairie-chickens. Mol. Ecol. 4695-4706.

Bouma, G., Crusius, J.B., Oudkerk Pool, M., Kolkman, J.J., von Blomberg, B.M., Kostense, P.J., Giphart, M.J., Schreuder, G.M., Meuwissen, S.G., Pena, A.S., 1996. Secretion of tumour necrosis factor alpha and lymphotoxin alpha in relation to polymorphisms in the TNF genes and HLA-DR alleles. Relevance for inflammatory bowel disease. Scand. J. Immunol. 43, 456-463.

Bowie, A.G., Haga, I.R., 2005. The role of Toll-like receptors in the host response to viruses. Mol. Immunol. 42, 859-867.

Bryja, J., Charbonnel, N., Berthier, K., Galan, M., Cosson, J.F., 2007. Density-related changes in selection pattern for major histocompatibility complex genes in fluctuating populations of voles. Mol. Ecol. 16, 5084-5097.

Burton, C., Krebs, C.J., Taylor, E.B., 2002. Population genetic structure of the cyclic snowshoe hare (Lepus americanus) in southwestern Yukon, Canada. Mol. Ecol. 11, 1689-1701.

Chapuis, M.P., Estoup, A., 2007. Microsatellite null alleles and estimation of population differentiation. Mol. Biol. Evol. 24, 621-631.

Charbonnel, N., Cosson, J.-F., 2011. Molecular epidemiology of disease resistance genes with perspectives for researches on biological invasions and hybrid zones. In: S, M Beaudeau, F., Cabaret, J., de Rycke, J. (Eds.), New Frontiers of Molecular Epidemiology of Infectious Diseases. Springer Netherlands, Dordrecht, pp. 255-290.

Charbonnel, N., Pagès, M., Sironen, T., Henttonen, H., Vapalahti, O., Mustonen, J., Vaheri, A. 2014. Immunogenetic factors affecting susceptibility of humans and rodents to hantaviruses and the clinical course of hantaviral disease in humans. Viruses 6, 2214-2241.

Clement, J., Maes, P., Van Ypersele De Strihou, C., Van Der Groen, G., Barrios, J.M., Verstraeten, W.W., Van Ranst, M., 2010. Beechnuts and outbreaks of nephropathia epidemica (NE): Of mast, mice and men. Nephrol. Dial. Transplant. 25, 1740-1746.

Coulon, A., Cosson, J.-F., Morellet, N., Angibault, J.-M., Cargnelutti, B., Galan, M., Aulagnier, S., Hewison, A.J.M., 2006. Dispersal is not female biased in a resource-defence mating ungulate, the European roe deer. Proc. Biol. Sci. 273, 341-348.

Deter, J., Chaval, Y., Galan, M., Gauffre, B., Morand, S., Henttonen, H., Laakkonen, J., Voutilainen, L., Charbonnel, N., Cosson, J.-F., 2008. Kinship, dispersal and hantavirus transmission in bank and common voles. Arch. Virol. 153, 435-444.

Ehrich, D., Jorde, P.E., Krebs, C.J., Kenney, A.J., Stacy, J.E., Stenseth, N.C., 2001. Spatial structure of lemming populations (Dicrostonyx groenlandicus) fluctuating in density. Mol. Ecol. 10, 481-495.

Ehrich, D., Yoccoz, N.G., Ims, R.A., 2009. Multi-annual density fluctuations and habitat size enhance genetic variability in two northern voles. Oikos 118, 1441-1452.

Ejsmond, M.J., Radwan, J., 2011. MHC diversity in bottlenecked populations: a simulation model. Conserv. Genet. 12, 129-137.

El Mousadik, A., Petit, R., 1996. High level of genetic differentiation for allelic richness among populations of the argan tree [Argania spinosa (L.) Skeels] endemic to Morocco. Theor. Appl. Genet. 92, 832-839.

Evanno, G., Regnaut, S., Goudet, J., 2005. Detecting the number of clusters of individuals using the software STRUCTURE: a simulation study. Mol. Ecol. 14, 2611-2620.

Excoffier, L., Lischer, H.E.L., 2010. Arlequin suite ver 3.5: a new series of programs to perform population genetics analyses under Linux and Windows. Mol. Ecol. Resour. 10, 564-567.

Foll, M., Gaggiotti, O., 2006. Identifying the environmental factors that determine the genetic structure of populations. Genetics 174, 875-891.

Fornůsková, A., Vinkler, M., Pagès, M., Galan, M., Jousselin, E., Cerqueira, F., Morand, S., Charbonnel, N., Bryja, J., Cosson, J.-F., 2013. Contrasted evolutionary histories of two Toll-like receptors (Tlr4 and Tlr7) in wild rodents (MURINAE). BMC Evol. Biol. 13.
Fornůsková, A., Bryja, J., Vinkler, M., Macholán, M., Piálek, J., 2014. Contrasting patterns of polymorphism and selection in bacterial-sensing toll-like receptor 4 in two house mouse subspecies. Ecol. Evol. 4, 2931-2944.

Frankham, R., 1995. Effective population size/adult population size ratios in wildlife: a review. Genet. Res. 66, 95-107.

Fraser, B., Ramnarine, I., Neff, B., 2010. Temporal variation at the Mhc class IIB in wild populations of the guppy (Poecilia reticulata). Evolution (N.Y.) 64, 2086-2096.

Galan, M., Razzauti, M., Bard, E., Bernard, M., Brouat, C., Charbonnel, N., Dehne-garcia, A., Loiseau, A., Tatard, C., Tamisier, L., Vayssier-taussat, M., 2016. 16S rRNA amplicon sequencing for epidemiological surveys of bacteria in wildlife: the importance of cleaning post-sequencing data before estimating positivity, prevalence and coinfection. mSystems 1, e00032-16.

García-Navas, V., Bonnet, T., Waldvogel, D., Wandeler, P., Camenisch, G., Postma, E., 2015 Gene flow counteracts the effect of drift in a Swiss population of snow voles fluctuating in size. Biol. Conserv. 191, 168-177.

Gauffre, B., Berthier, K., Inchausti, P., Chaval, Y., Bretagnolle, V., Cosson, J.F., 2014. Shortterm variations in gene flow related to cyclic density fluctuations in the common vole. Mol. Ecol. 23, 3214-3225.

Goudet, J., 1995. FSTAT (version 1.2): a computer program to calculate F-statistics. J. Hered. 86, 485-486.

Grueber, C.E., Wallis, G.P., Jamieson, I.G., 2013. Genetic drift outweighs natural selection at toll-like receptor (TLR) immunity loci in a re-introduced population of a threatened species. Mol. Ecol. 22, 4470-4482.

Guivier, E., Galan, M., Salvador, A.R., Xuéreb, A., Chaval, Y., Olsson, G.E., Essbauer, S. Henttonen, H., Voutilainen, L., Cosson, J.-F., Charbonnel, N., 2010. Tnf- $\alpha$ expression and promoter sequences reflect the balance of tolerance/resistance to Puumala hantavirus infection in European bank vole populations. Infect. Genet. Evol. 10, 1208-1217.

Guivier, E., Galan, M., Chaval, Y., Xuéreb, A., Ribas Salvador, A., Poulle, M.-L., Voutilainen, L., Henttonen, H., Charbonnel, N., Cosson, J.F., 2011. Landscape genetics highlights the role of bank vole metapopulation dynamics in the epidemiology of Puumala hantavirus. Mol. Ecol. 20, 3569-3583.

Guivier, E., Galan, M., Henttonen, H., Cosson, J.-F., Charbonnel, N., 2013. Landscape features and helminth co-infection shape bank vole immunoheterogeneity, with consequences for Puumala virus epidemiology. Heredity (Edinb). 112, 274-281.

Haldane, B.J., 1956. The estimation and significance of the logarithm of a ratio of frequencies. Ann. Hum. Genet. 20, 309-311.

Hanski, I., Henttonen, H., 2002. Population cycles of small rodents in Fennoscandia. In: Berryman, A. (Ed.), Populations Cycles: The Case for Trophic Interactions, pp. 44-68.

Hansson, L., 1986. Geographic differences in the sociability of voles in relation to cyclicity. Anim. Behav. 34, 1215-1221.

Hansson, B., Henttonen, H., 1988. Rodent dynamics as community processes. Trends Ecol Evol. 8, 195-200.

Hardy, O., Vekemans, X., 2002. SPAGeDi: a versatile computer program to analyse spatial genetic structure at the individual or population levels. Mol. Ecol. Notes 2, 618-620.

Henttonen, H., McGuire, A.D., Hansson, L., 1985. Comparisons of amplitudes and frequencies (spectral analyses) of density variations in long-term data sets of Clethrionomys species. Ann. Zool. Fenn. 22, 221-227.

Hughes, A.L., Piontkivska, H., 2008. Functional diversification of the toll-like receptor gene family. Immunogenetics 60, 249-256.

Jakobsson, M., Rosenberg, N.A., 2007. CLUMPP: a cluster matching and permutation program for dealing with label switching and multimodality in analysis of population structure. Bioinformatics 23, 1801-1806.

Janzen, C., Kochs, G., Haller, O., 2000. A monomeric GTPase-negative MxA mutant with antiviral activity. J. Virol. 74, 8202-8206.

Jin, H.K., Takada, A., Kon, Y., Haller, O., Watanabe, T., 1999. Identification of the murine Mx2 gene: interferon-induced expression of the Mx2 protein from the feral mouse gene confers resistance to vesicular stomatitis virus. J. Virol. 73, 4925-4930.

Jin, H.K., Yoshimatsu, K., Takada, A., Ogino, M., Asano, A., Arikawa, J., Watanabe, T., 2001 Mouse Mx2 protein inhibits hantavirus but not influenza virus replication. Arch. Virol. 146, 41-49.

Kallio, E.R., Klingström, J., Gustafsson, E., Manni, T., Vaheri, A., Henttonen, H., Vapalahti, O., Lundkvist, A., 2006a. Prolonged survival of Puumala hantavirus outside the host: evidence for indirect transmission via the environment. J. Gen. Virol. 87, 2127-2134.

Kallio, E.R., Poikonen, A., Vaheri, A., Vapalahti, O., Henttonen, H., Koskela, E., Mappes, T. 2006b. Maternal antibodies postpone hantavirus infection and enhance individual breeding success. Proc. R. Soc. B Biol. Sci. 273, 2771-2776.

Kallio, E.R., Voutilainen, L., Vapalahti, O., Vaheri, A., Henttonen, H., Koskela, E., Mappes, T. 2007. Endemic hantavirus infection impairs the winter survival of its rodent host Ecology 88, 1911-1916.

Kallio, E.R., Helle, H., Koskela, E., Mappes, T., Vapalahti, O., 2015. Age-related effects of chronic hantavirus infection on female host fecundity. J. Anim. Ecol. 84, 1264-1272.

Kallio-Kokko, H., Laakkonen, J., Rizzoli, A., Tagliapietra, V., Cattadori, I., Perkins, S.E. Hudson, P.J., Cristofolini, A., Versini, W., Vapalahti, O., Vaheri, A., Henttonen, H. 2006. Hantavirus and arenavirus antibody prevalence in rodents and humans in Trentino, Northern Italy. Epidemiol. Infect. 134, 830-836.

Kochs, G., Haller, O., 1999. Interferon-induced human MxA GTPase blocks nuclear import of Thogoto virus nucleocapsids. Proc. Natl. Acad. Sci. U. S. A. 96, 2082-2086.

Le Galliard, J., Rémy, A., Ims, R., Lambin, X., 2012. Patterns and processes of dispersal behaviour in arvicoline rodents. Mol. Ecol. 21, 505-523.

Lee, S.H., Vidal, S.M., 2002. Functional diversity of Mx proteins: variations on a theme of host resistance to infection. Genome Res. 12, 527-530.

Li, C.C., Weeks, D.E., Chakravarti, A., 1993. Similarity of DNA finger prints due to chance and relatedness. Hum. Hered. 43, 45-52.

Lotterhos, K.E., Whitlock, M.C., 2014. Evaluation of demographic history and neutral parameterization on the performance of FST outlier tests. Mol. Ecol. 23, 2178-2192.

Maruyama, T., Fuerst, P.A., 1985. Population bottlenecks and nonequilibrium models in population genetics. II. Number of alleles in a small population that was formed by a recent bottleneck. Genetics 111, 675-689.

Meyer, B.J., Schmaljohn, C.S., 2000. Persistent hantavirus infections: characteristics and mechanisms. Trends Microbiol. 8, 61-67. 
Nei, M., 1978. Estimation of average heterozygosity and genetic distance from a small number of individuals. Genetics 89, 583-590.

Nei, M., Maruyama, T., Chakraborty, R., 1975. The bottleneck effect and genetic variability in populations. Evolution (N.Y.) 29, 1-10.

Oliver, M.K., Piertney, S.B., 2012. Selection maintains MHC diversity through a natural population bottleneck. Mol. Biol. Evol. 29, 1713-1720.

Pilot, M., Dabrowski, M.J., Jancewicz, E., Schtickzelle, N., Gliwicz, J., 2010. Temporally stable genetic variability and dynamic kinship structure in a fluctuating population of the root vole Microtus oeconomus. Mol. Ecol. 19, 2800-2812.

Porter, B.F., Ambrus, A., Storts, R.W., 2006. Immunohistochemical evaluation of Mx protein expression in canine encephalitides. Vet. Pathol. 43, 981-987.

Price, P.W., 1980. Evolutionary Biology of Parasites (Vol. 15). Princeton University Press.

Pritchard, J.K., Stephens, M., Donnelly, P., 2000. Inference of population structure using multilocus genotype data. Genetics 155, 945-959.

Prugnolle, F., Meeûs, T.D., 2002. Inferring sex-biased dispersal from population genetic tools: a review. Heredity (Edinb). 161-165.

Quéméré, E., Galan, M., Cosson, J.-F., Klein, F., Aulagnier, S., Gilot-Fromont, E., Merlet, J. Bonhomme, M., Hewison, A.J.M., Charbonnel, N., 2015. Immunogenetic heterogeneity in a widespread ungulate: the European roe deer (Capreolus capreolus). Mol. Ecol. 24, 3873-3887.

R Core Team, 2013. R: A Language and Environment for Statistical Computing.

Ramensky, V., Bork, P., Sunyaev, S., 2002. Human non-synonymous SNPs: server and survey. Nucleic Acids Res. 30, 3894-3900.

Raymond, M., Rousset, F., 1995. An exact test for population differentiation. Evolution (N.Y.) 49, 1283.

Razzauti, M., Plyusnina, A., Henttonen, H., Plyusnin, A., 2008. Accumulation of point mutations and reassortment of genomic RNA segments are involved in the microevolution of Puumala hantavirus in a bank vole (Myodes glareolus) population. J. Gen. Virol. 89, 1649-1660.

Razzauti, M., Plyusnina, A., Henttonen, H., Plyusnin, A., 2013. Microevolution of Puumala hantavirus during a complete population cycle of its host, the bank vole (Myodes glareolus). PLoS One 8, e64447.

Rikalainen, K., Grapputo, A., Knott, E., Koskela, E., Mappes, T., 2008. A large panel of nove microsatellite markers for the bank vole (Myodes glareolus). Mol. Ecol. Resour. 8 1164-1168.

Rikalainen, K., Aspi, J., Galarza, J.A., Koskela, E., Mappes, T., 2012. Maintenance of genetic diversity in cyclic populations-a longitudinal analysis in Myodes glareolus. Ecol. Evol. 2, 1491-1502.

Rohfritsch, P.A., Guivier, E., Galan, M., Chaval, Y., Cosson, J.F., Charbonnel, N., 2013. Apport de l'immunogénétique à la compréhension des interactions entre le campagnol roussâtre Myodes glareolus et l'hantavirus puumala. Bull. Acad. Vet. Fr. 166, 171-183.

Rosenberg, N.A., 2004. Distruct: a program for the graphical display of population structure. Mol. Ecol. Notes 4, 137-138.

Sabeti, P.C., Varilly, P., Fry, B., Lohmueller, J., Hostetter, E., Cotsapas, C., Xie, X., Byrne, E.H., McCarroll, S.A., Gaudet, R., Schaffner, S.F., Lander, E.S., and The International HapMap Consortium, 2007. Genome-wide detection and characterization of positive selection in human populations. Nature 449, 913-918.

Scott, D., 2002. Multivariate Density Estimation: Theory, Practice, and Visualization. John Wiley \& Sons, 1992
Ségurel, L., Lafosse, S., Heyer, E., Vitalis, R., 2010. Frequency of the AGT Pro11Leu polymorphism in humans: Does diet matter? Ann. Hum. Genet. 74, 57-64.

Sutton, J.T., Nakagawa, S., Robertson, B.C., Jamieson, I.G., 2011. Disentangling the roles of natural selection and genetic drift in shaping variation at MHC immunity genes. Mol. Ecol. 20, 4408-4420.

Tersago, K., Crespin, L., Verhagen, R., Leirs, H., 2012. Impact of Puumala virus infection on maturation and survival in bank voles: a capture-mark-recapture analysis. J. Wildl. Dis. $48,148-156$

Turner, A.K., Begon, M., Jackson, J.A., Paterson, S., 2012. Evidence for selection at cytokine loci in a natural population of field voles (Microtus agrestis). Mol. Ecol. 21, 1632-1646.

Vaheri, A., Henttonen, H., Voutilainen, L., Mustonen, J., Sironen, T., Vapalahti, O., 2012. Hantavirus infections in Europe and their impact on public health. Rev. Med. Virol. Virol. 23, 35-49.

Vassalli, P., 1992. The pathophysiology of Tumor Necrosis Factor. Annu. Rev. Immunol. 10, $411-452$

Vekemans, X., Hardy, O.J., 2004. New insights from fine-scale spatial genetic structure analyses in plant populations. Mol. Ecol. 13, 921-935.

Voutilainen, L., Sironen, T., Tonteri, E., Bäck, A.T., Razzauti, M., Karlsson, M., Wahlström, M., Niemimaa, J., Henttonen, H., Lundkvist, Å., 2015a. Life-long shedding of Puumala hantavirus in wild bank voles (Myodes glareolus). J. Gen. Virol. 96, 1238-1247.

Voutilainen, L., Sironen, T., Tonteri, E., Bäck, A.T., Razzauti, M., Karlsson, M., Wahlström, M., Niemimaa, J., Henttonen, H., Lundkvist, Å., Tuiskunen Back, A., Razzauti, M., Karlsson, M., Wahlstrom, M., Niemimaa, J., Henttonen, H., Lundkvist, A., 2015b. Life-long shedding of Puumala hantavirus in wild bank voles (Myodes glareolus). J. Gen. Virol. 96, $1238-1247$.

Voutilainen, L., Kallio, E.R., Niemimaa, J., Vapalahti, O., Henttonen, H., 2016. Temporal dynamics of Puumala hantavirus infection in cyclic populations of bank voles. Sci. Rep. 6.

Wachowiak, W, Balk, P. A, Savolainen, 0, 2009. Search for nucleotide diversity patterns of local adaptation in dehydrins and other cold-related candidate genes in Scots pine (Pinus sylvestris L.). Tree Genet. Genome 5, 117-132.

Weber de Melo, V., Sheikh Ali, H., Freise, J., Kühnert, D., Essbauer, S., Mertens, M., Wanka, K.M., Drewes, S., Ulrich, R.G., Heckel, G., 2015. Spatiotemporal dynamics of Puumala hantavirus associated with its rodent host, Myodes glareolus. Evol. Appl. 8, 545-559.

Weir, B., Cockerham, C., 1984. Estimating F-statistics for the analysis of population structure. Evolution (N.Y.) 38, 1358-1370.

Wilson, A.G., Symons, J.A., McDowell, T.L., McDevitt, H.O., Duff, G.W., 1997. Effects of a polymorphism in the human tumor necrosis factor alpha promoter on transcriptional activation. Proc. Natl. Acad. Sci. U. S. A. 94, 3195-3199.

Winternitz, J.C., Wares, J.P., Yabsley, M.J., Altizer, S., 2014. Wild cyclic voles maintain high neutral and MHC diversity without strong evidence for parasite-mediated selection. Evol. Ecol. 28, 957-975.

Wlasiuk, G., Nachman, M.W., 2010. Adaptation and constraint at toll-like receptors in primates. Mol. Biol. Evol. 27, 2172-2186.

Zürcher, T., Pavlovic, J., Staeheli, P., 1992. Mechanism of human MxA protein action: variants with changed antiviral properties. EMBO J. 11, 1657-1661. 